\title{
Area-Selective ZnO Thin Film Deposition on Variable Microgap Electrodes and Their Impact on UV Sensing
}

\author{
Q. Humayun, M. Kashif, and U. Hashim \\ Nano Biochip Research Group, Institute of Nano Electronic Engineering (INEE), Universiti Malaysia Perlis (UniMAP), 01000 Kangar, \\ Perlis, Malaysia
}

Correspondence should be addressed to Q. Humayun; qhumayun2@gmail.com

Received 4 January 2013; Revised 7 April 2013; Accepted 20 May 2013

Academic Editor: Gong Ru Lin

Copyright (C) 2013 Q. Humayun et al. This is an open access article distributed under the Creative Commons Attribution License, which permits unrestricted use, distribution, and reproduction in any medium, provided the original work is properly cited.

$\mathrm{ZnO}$ thin films were deposited on patterned gold electrodes using the sol-gel spin coating technique. Conventional photolithography process was used to obtain the variable microgaps of 30 and $43 \mu \mathrm{m}$ in butterfly topology by using zero-gap chrome mask. The structural, morphological, and electrical properties of the deposited thin films were characterized by X-ray diffraction (XRD), scanning electron microscope (SEM), and Keithley SourceMeter, respectively. The current-voltage $(I-V)$ characterization was performed to investigate the effect of UV light on the fabricated devices. The $\mathrm{ZnO}$ fabricated sensors showed a photo to dark current $\left(I_{\mathrm{ph}} / I_{\mathrm{d}}\right)$ ratios of 6.26 for $30 \mu \mathrm{m}$ and 5.28 for $43 \mu \mathrm{m}$ gap electrodes spacing, respectively. Dynamic responses of both fabricated sensors were observed till $1 \mathrm{~V}$ with good reproducibility. At the applied voltage of $1 \mathrm{~V}$, the response time was observed to be $4.817 \mathrm{~s}$ and $3.704 \mathrm{~s}$ while the recovery time was observed to be $0.3738 \mathrm{~s}$ and $0.2891 \mathrm{~s}$ for 30 and $43 \mu \mathrm{m}$ gaps, respectively. The signal detection at low operating voltages suggested that the fabricated sensors could be used for miniaturized devices with low power consumption.

\section{Introduction}

The emergence of nanomaterial-based devices in the market motivates the researchers to fabricate different low-cost highthroughput sensors. Ultraviolet (UV) photodetectors have drawn a great deal of attention in recent years in various commercial and military applications, such as secure spaceto-space communications, pollution monitoring, water sterilization, flame sensing, and early missile plume detection [1]. Zinc oxide has attracted much research attention because of its unique properties such as high surface-to-volume ratios [2], wide direct band gap $\left(\mathrm{E}_{g}=3.37 \mathrm{eV}\right)$, and high exciton binding energy $(60 \mathrm{meV})$. In comparison with $\mathrm{GaN}, \mathrm{ZnO}$ thin film have maximum electron saturation velocity; therefore, $\mathrm{ZnO}$-based photodetectors can attain the maximum operation speed [3].

$\mathrm{ZnO}$ nanostructures can be synthesized via variety of methods including MOCVD [4], thermal evaporation [5], molecular beam epitaxy (MBE) [6], electrochemical deposition [7], spray pyrolysis [8], and sol-gel [9]. Among these methods, the sol-gel technique is the simplest and least expensive. One-dimensional $\mathrm{ZnO}$ nanostructures are gaining great attention because of their potential applications in nanoscale electronic and optoelectronic devices $[10,11]$.

Metal-semiconductor-metal (MSM) Schottky barrier diodes are attractive photodetectors because of their low dark current, fast response, superior responsivity, and also direct compatibility with modern high-speed integrated circuitry [12]. To fabricate sensitive and selective metal-semiconductor-metal (MSM) photosensor, the most significant factor is to obtain large Schottky barrier height at interface, because large Schottky barrier height generates small leakage current and maximum breakdown voltage which exaggerate the responsivity and photo-to-dark-current contrast ratio [13]. Therefore, verities of photo-sensors including $p-n$ junction, metal-semiconductor-metal, and Schottky diodes have been fabricated, but due to simple structure and low cost, metal-semiconductor-metal photo sensors are getting the market value [14]. However, the maximum decay time and maximum dark current are the failure of photoconductive kind photo sensors, but still all the reported photoconductive type ultraviolet sensors perform maximum gain [15]. 
In the current research, 30 and $43 \mu \mathrm{m}$ gap gold electrodes were patterned using conventional lithography technique. The area-selective deposition of $\mathrm{ZnO}$ thin film was carried out using low-cost sol-gel spin coating technique. To investigate the effect of different microgaps on the current-to-voltage ( $I$ $V)$ characteristics, the fabricated devices were tested under dark and UV environment.

\section{Experimental}

$\mathrm{ZnO}$ seed solution was prepared as reported in our previous work [16]. In short, $0.5 \mathrm{M}$ of zinc acetate dihydrate was dissolved in 2-methoxyethanol, and monoethanolamine (MEA) was added as a stabilizer. The molar ratio of MEA to zinc acetate dehydrate $\left(\mathrm{Zn}\left(\mathrm{CH}_{3} \mathrm{COO}\right)_{2}\right)$ was maintained at 1.0. The p-type (100) silicon substrates were cleaned with RCA1 and RCA2 followed by dipping in diluted hydrofluoric acid (HF) to remove the native oxide layer. After the wafer cleaning step, an oxide layer of $\sim 1 \mu \mathrm{m}$ thickness was grown through a wet oxidation process. The oxide layer was used to isolate the film from the silicon wafer. A thin layer of titanium (Ti) and gold $(\mathrm{Au})$ metals were deposited using auto306 vacuum thermal evaporator. Zero-gap chrome mask was used in the butterfly topology to create variable microgaps of 30 and $43 \mu \mathrm{m}$, respectively. $\mathrm{ZnO}$ seed layer was deposited on patterned oxidized silicon substrates using a spin coater rotating at $3000 \mathrm{rpm}$ for $45 \mathrm{~s}$. After coating the seed layer, the films were dried at $300^{\circ} \mathrm{C}$ for $15 \mathrm{~min}$ to evaporate the solvent and remove the organic residuals. The coating and drying processes were repeated 5 times. After depositing 5 successive layers, the samples were incubated in a furnace to anneal the thin films at $400^{\circ} \mathrm{C}$ for $1 \mathrm{~h}$ under air environment. To obtain the output signal from the electrodes, a portion of the $\mathrm{ZnO}$ covered gold electrodes were etched using $2 \%$ HCL to remove the $\mathrm{ZnO}$.

The structural properties of the $\mathrm{ZnO}$ thin films were investigated using an X-ray diffractometer (Bruker D8) with $\mathrm{Cu} \mathrm{K} \alpha$ radiation at $\lambda=0.154 \mathrm{~nm}$. Morphological studies were performed using a scanning electron micrograph (SEM). A UV LED with a wavelength of $365 \mathrm{~nm}$ and power of $2 \mathrm{~mW}$ was used as the illuminating source. A Keithley 2400 SourceMeter was used to measure the current-to-voltage $(I-V)$ and current-to-time $(I-t)$ characteristics. All the measurements were carried out under ambient environment.

\section{Results and Discussion}

The XRD pattern of the $\mathrm{ZnO}$ thin films is shown in Figure 1. The XRD spectra demonstrated several peaks at (100), (002), (101), (102), and (103) planes. The crystalline size of the $\mathrm{ZnO}$ thin films at (002) peak was calculated using the Scherrer formula [17]:

$$
D=\frac{0.9 \lambda}{B \cos \theta}
$$

where $\lambda$ is the wavelength, $\theta$ is the Bragg angle, and $B$ is the FWHM value. The calculated value for the crystalline size was

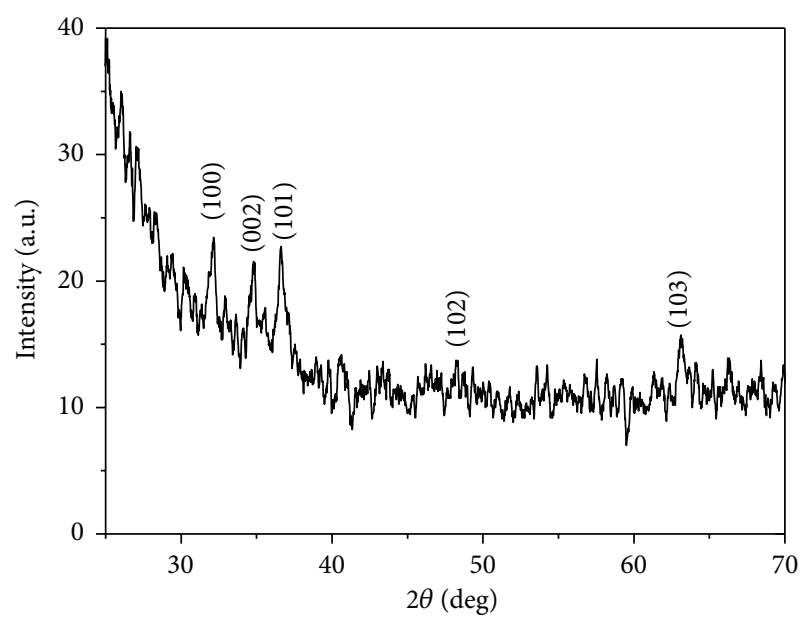

Figure 1: XRD spectra of deposited $\mathrm{ZnO}$ thin film.

$31.5 \mathrm{~nm}$. The lattice constant " $c$ " for the $\mathrm{ZnO}$ nanostructures was calculated using the Bragg's law [17]:

$$
n \lambda=2 d \sin \theta \text {, }
$$

where $n$ is the order of diffraction, $\lambda$ is the X-ray wavelength, and $d$ is the spacing between planes of given Miller indices $h$, $k$, and $l$. The plane spacing is related to the lattice constants " $a$ " and " $c$ " and the Miller indices by the following relation [17]:

$$
d_{h k l}=\sqrt{\frac{4}{3} \frac{\left(h^{2}+h k+k^{2}\right)}{a^{2}}+\frac{l^{2}}{c^{2}}} .
$$

The calculated value for lattice constant " $c$ " was found to be $5.15 \AA$. The calculated lattice parameter $c$ is in good agreement with the reported value [17].

The scanning electron micrograph depicting the morphological feature of $\mathrm{ZnO}$ thin films deposited on patterned gold microgap electrodes is shown in Figures 2(a), 2(b), and 2(c). It can be observed that the whole surface is covered with the $\mathrm{ZnO}$ nanoparticles and the deposited film depicted rough surface with porosity and small particles that are connected to each other. Figure 2(d) shows the captured image of zero-gap chrome mask.

Figures 3(a) and 3(b) show the current-to-voltage $(I-V)$ characteristics of the fabricated devices with and without UV illumination. It was notified that, with exposure to UV light, the current increased from $5.83 \mu \mathrm{A}$ to $36.5 \mu \mathrm{A}$ for $30 \mu \mathrm{m}$ and $10.89 \mu \mathrm{A}$ to $57.5 \mu \mathrm{A}$ for $43 \mu \mathrm{m}$ gap. The results indicate that both the UV sensors showed noticeable changes when the devices were exposed to UV light. The photocurrentto-dark $\left(I_{\mathrm{ph}} / I_{\mathrm{d}}\right)$ ratio for the fabricated sensors having the microgap of 30 and $43 \mu \mathrm{m}$ was found to be 6.28 and 5.28, respectively. The calculated values for photocurrent-to-dark $\left(I_{\mathrm{ph}} / I_{\mathrm{d}}\right)$ ratio reflected that the fabricated devices displayed the higher photocurrent-to-dark $\left(I_{\mathrm{ph}} / I_{\mathrm{d}}\right)$ ratios over the literature documented reports $[18,19]$.

Figures 4(a) and 4(b) show the reproducibility curves of the fabricated devices. From the figures, it can be visually 


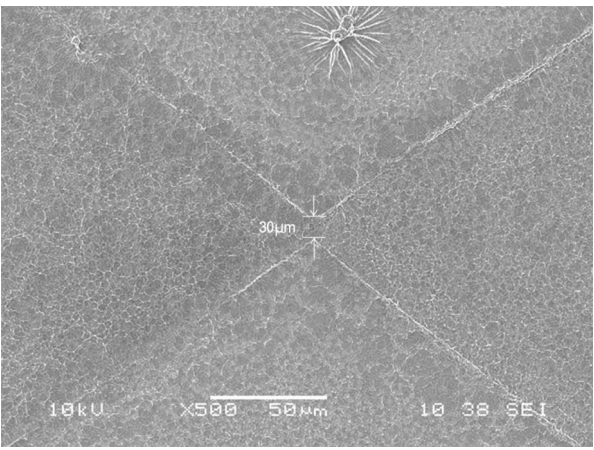

(a)

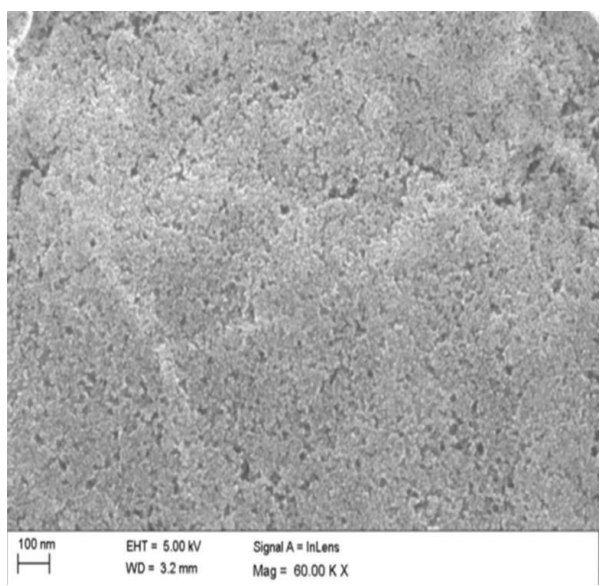

(c)

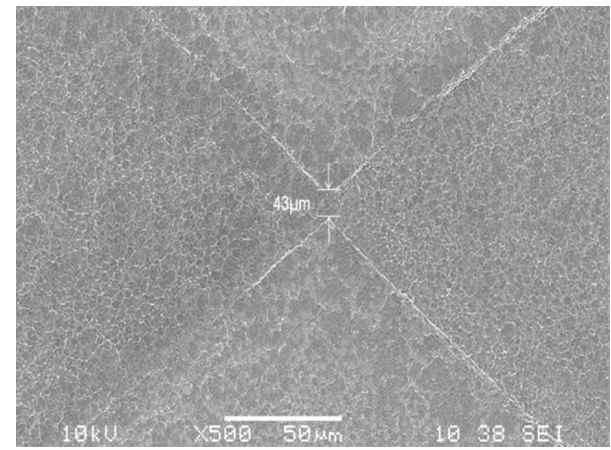

(b)

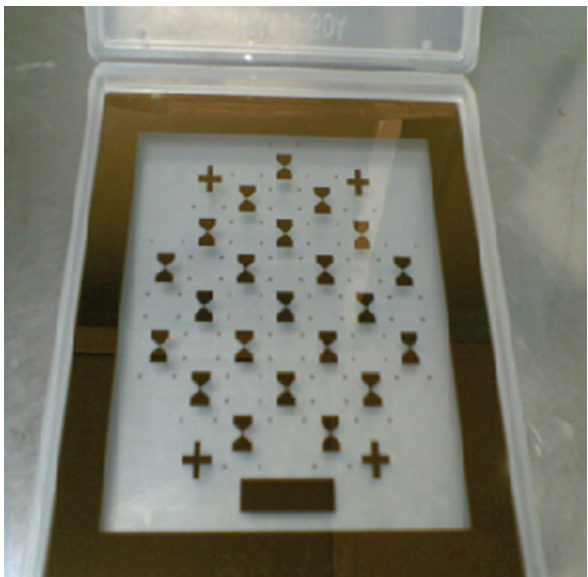

(d)

Figure 2: (a, b, and c) SEM images of $\mathrm{ZnO}$ thin films and (d) top view of zero-gap chrome mask.

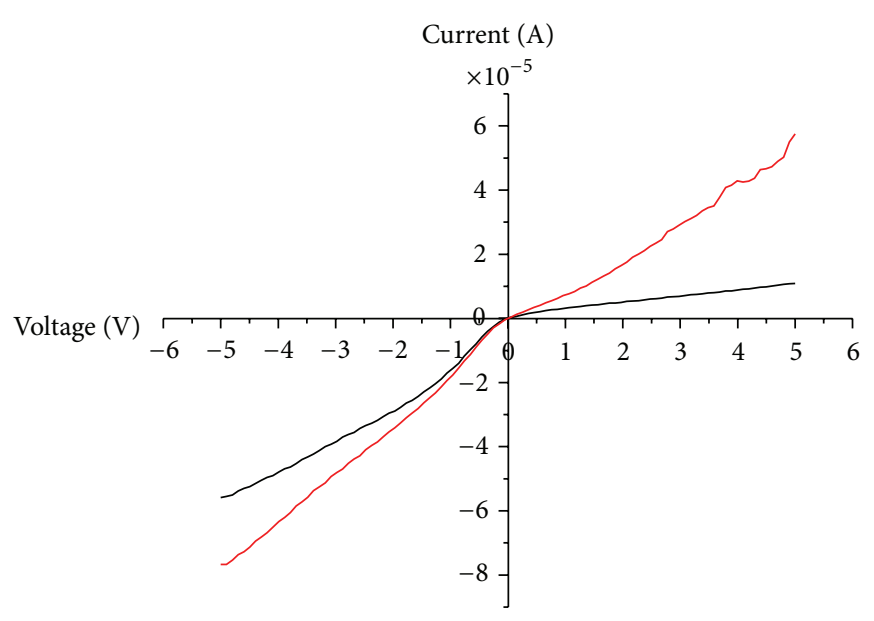

- Dark

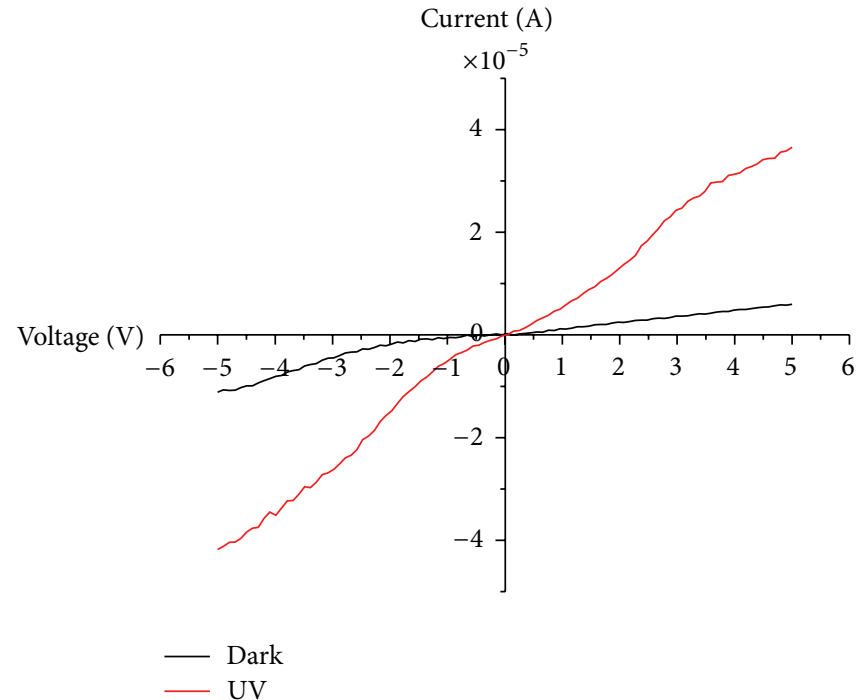

(b)

FIGURE 3: $I$ - $V$ characteristics for $\mathrm{ZnO}$ thin film photodetector under UV and dark environment for (a) $30 \mu \mathrm{m}$ and (b) $43 \mu \mathrm{m}$ gaps. 


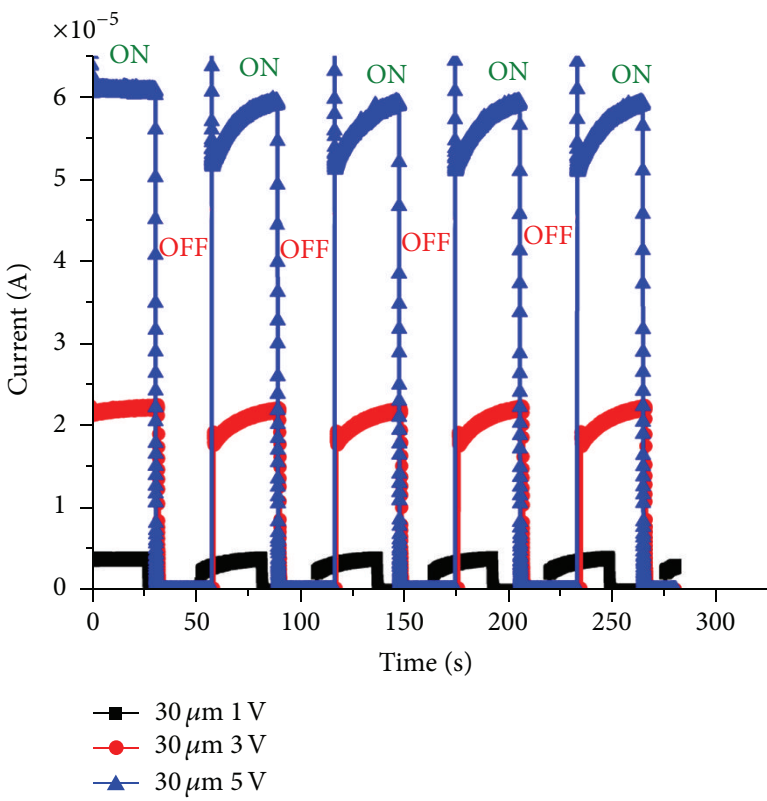

(a)

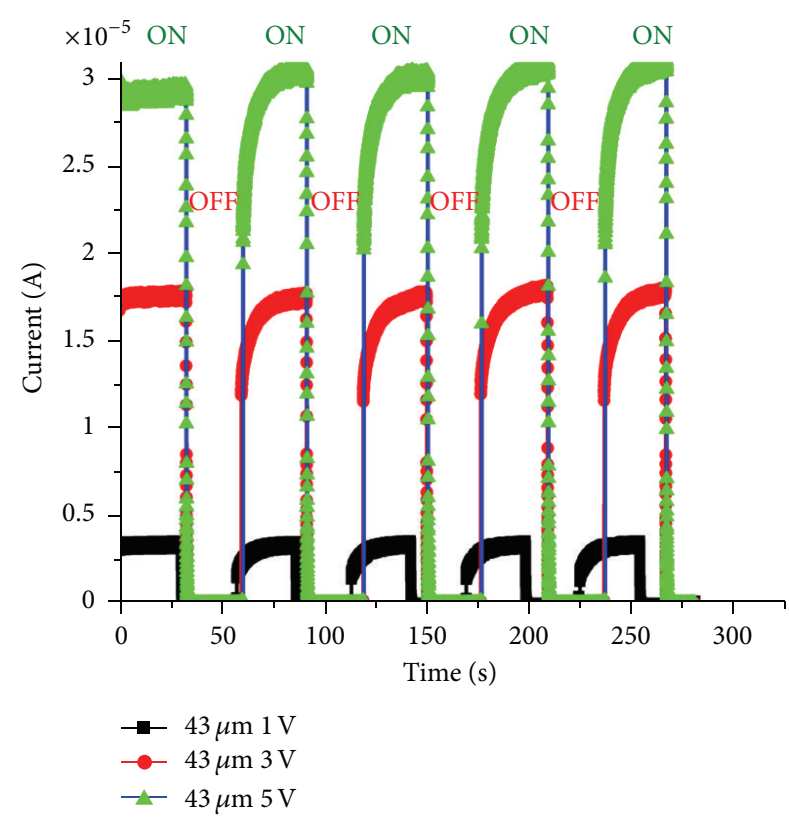

(b)

FIGURE 4: Transient responses of the photoconductor devices to UV illumination under different bias voltages for (a) $30 \mu \mathrm{m}$ and (b) $43 \mu \mathrm{m}$ gaps.

inspected that both the devices showed good reproducibility. The sensors were tested under different applied voltages, and it was observed that the sensors respond nicely and displayed reproducible response till $1 \mathrm{~V}$. From the curves, it can be revealed that the fabricated devices can be used for lowpower miniaturized devices with fast detection capability and reproducibility. The response time was defined as the time taken by the sensor to achieve at least $90 \%$ variation in current flow with respect to its baseline value. The recovery time was the time taken by the sensor to achieve at least $10 \%$ variation in current flow to reach its initial value after switching off the UV LED. At the applied voltage of $1 \mathrm{~V}$, the calculated values for the response and recovery time for 30 and $43 \mu \mathrm{m}$ gaps were found to be $(4.817 \mathrm{~s}, 0.3738 \mathrm{~s})$ and $(3.704 \mathrm{~s}, 0.2891 \mathrm{~s})$, respectively.

The interelectrode spacing played a very crucial role to enhance the photoresponse signal output. The decrement in the electrode spacing resulted in the enhancement of photoresponse signal output [20]. The close spacing between the electrodes results in the creation of stronger electrode field across the electrodes, which favors strong charge separation and minimized the recombination of photogenerated carriers [20]. Therefore, at small electrodes spacing the width of the depletion layer at grain boundaries decreased due to the increase in carrier concentration [20]. Moreover, the decrement in electrodes spacing revealed high photocurrent value when the sensor was exposed to ultraviolet light [21]. The reactions on $\mathrm{ZnO}$ film surface during UV illumination can be described using the following equations [20]:

$$
\begin{aligned}
& \mathrm{O}_{2}+\mathrm{e}^{-} \longrightarrow \mathrm{O}_{2}{ }^{-} \\
& h \nu \longrightarrow \mathrm{h}^{+}+\mathrm{e}^{-}
\end{aligned}
$$

$$
\mathrm{O}_{2}{ }^{-}+\mathrm{h}^{+} \longrightarrow \mathrm{O}_{2}
$$

where $\mathrm{O}_{2}$ is the oxygen molecule, $\mathrm{e}^{-}$is the free electron, $\mathrm{O}_{2}{ }^{-}$ is the adsorbed oxygen, $h v$ is the photon energy of the UV light, $h^{+}$is the photogenerated hole in the valence band, and $e^{-}$is the photogenerated electron in the conduction band. It can be concluded from the previously stated relations that the negative-charged oxygen ions adsorbed on the surface of $\mathrm{ZnO}$ can be discharged by photogenerated hole, which produce free electron in the conduction band [22]. The maximum numbers of oxygen molecules rapidly come out from the $\mathrm{ZnO}$ surface after ultraviolet illumination, which produce fast response to the ultraviolet light [23]. On the other hand when the ultraviolet light is turned OFF, the oxygen molecules reabsorb on the $\mathrm{ZnO}$ surface, returning the device to its initial value [24]. It was notified that $30 \mu \mathrm{m}$ microgap electrodes spacing displayed maximum rise and decay time constants. The increment in the rise and decay time can be attributed due to longer carrier lifetime by the smaller interelectrode distance [20].

\section{Conclusions}

$\mathrm{ZnO}$ thin films were successfully deposited on patterned gold microgap electrodes using low-cost sol-gel spin coating method. The fabricated sensors with different microgap electrodes of 30 and $43 \mu \mathrm{m}$ were tested under dark and UV conditions and showed noticeable changes under the exposure of UV light. The photocurrent-to-dark current ratio was found to be 6.28 and 5.28 for 30 and $43 \mu \mathrm{m}$ gap spacing. The reproducibility and fast response at low voltage showed 
that the fabricated sensor can be used for the UV sensing applications.

\section{Acknowledgments}

The authors acknowledge the financial support from the Ministry of Higher Education (MOHE). The authors would also like to thank the technical staff of the Institute of Nano Electronic Engineering and School of Microelectronic Engineering, Universiti Malaysia Perlis for their kind support to smoothly perform the research.

\section{References}

[1] S. S. Shinde and K. Y. Rajpure, "Fabrication and performance of $\mathrm{N}$-doped ZnO UV photoconductive detector," Journal of Alloys and Compounds, vol. 522, pp. 118-122, 2012.

[2] L. Guo, H. Zhang, D. Zhao et al., "High responsivity $\mathrm{ZnO}$ nanowires based UV detector fabricated by the dielectrophoresis method," Sensors and Actuators B, vol. 166-167, pp. 12-16, 2012.

[3] S. P. Chang, R. W. Chuang, S. J. Chang, C. Y. Lu, Y. Z. Chiou, and S. F. Hsieh, "Surface $\mathrm{HCl}$ treatment in $\mathrm{ZnO}$ photoconductive sensors," Thin Solid Films, vol. 517, no. 17, pp. 5050-5053, 2009.

[4] P. Biswas, S. Kundu, P. Banerji, and S. Bhunia, "Super rapid response of humidity sensor based on MOCVD grown $\mathrm{ZnO}$ nanotips array," Sensors and Actuators B, vol. 178, pp. 331-338, 2013.

[5] L. Feng, A. Liu, M. Liu, Y. Ma, J. Wei, and B. Man, "Fabrication and characterization of tetrapod-like $\mathrm{ZnO}$ nanostructures prepared by catalyst-free thermal evaporation," Materials Characterization, vol. 61, no. 1, pp. 128-133, 2010.

[6] H.-J. Ko, S.-K. Hong, Y. Chen, and T. Yao, "A challenge in molecular beam epitaxy of $\mathrm{ZnO}$ : control of material properties by interface engineering," Thin Solid Films, vol. 409, no. 1, pp. 153-160, 2002.

[7] S. Bai, C. Sun, T. Guo et al., "Low temperature electrochemical deposition of nanoporous $\mathrm{ZnO}$ thin films as novel $\mathrm{NO}_{2}$ sensors," Electrochimica Acta, vol. 90, pp. 530-534, 2013.

[8] M. Breedon, M. B. Rahmani, S.-H. Keshmiri, W. Wlodarski, and K. Kalantar-zadeh, "Aqueous synthesis of interconnected $\mathrm{ZnO}$ nanowires using spray pyrolysis deposited seed layers," Materials Letters, vol. 64, no. 3, pp. 291-294, 2010.

[9] M. Kashif, S. M. Usman Ali, M. E. Ali et al., "Morphological, optical, and Raman characteristics of $\mathrm{ZnO}$ nanoflakes prepared via a sol-gel method," Physica Status Solidi A, vol. 209, no. 1, pp. 143-147, 2012.

[10] C.-L. Hsu, K.-C. Chen, T.-Y. Tsai, and T.-J. Hsueh, "Fabrication of gas sensor based on $p$-type $\mathrm{ZnO}$ nanoparticles and n-type ZnO nanowires," Sensors and Actuators B, vol. 182, pp. 190-196, 2013.

[11] A. A. M. Farag, M. Cavas, F. Yakuphanoglu, and F. M. Amanullah, "Photoluminescence and optical properties of nanostructure $\mathrm{Ni}$ doped $\mathrm{ZnO}$ thin films prepared by sol-gel spin coating technique," Journal of Alloys and Compounds, vol. 509, no. 30, pp. 7900-7908, 2011.

[12] K. Liu, M. Sakurai, and M. Aono, "ZnO-based ultraviolet photodetectors," Sensors, vol. 10, no. 9, pp. 8604-8634, 2010.

[13] S. J. Young, L. W. Ji, S. J. Chang, and Y. K. Su, "ZnO metalsemiconductor-metal ultraviolet sensors with various contact electrodes," Journal of Crystal Growth, vol. 293, no. 1, pp. 43-47, 2006.

[14] S. J. Young, L. W. Ji, S. J. Chang et al., "ZnO-based MIS photodetectors," Sensors and Actuators A, vol. 135, no. 2, pp. 529-533, 2007.

[15] D. Jiang, J. Zhang, Y. Lu et al., "Ultraviolet Schottky detector based on epitaxial $\mathrm{ZnO}$ thin film," Solid-State Electronics, vol. 52, no. 5, pp. 679-682, 2008.

[16] M. Kashif, U. Hashim, M. E. Ali et al., "Effect of different seed solutions on the morphology and electrooptical properties of ZnO nanorods," Journal of Nanomaterials, vol. 2012, Article ID 452407, 6 pages, 2012.

[17] M. Kashif, U. Hashim, M. E. Ali, K. L. Foo, and S. M. Usman Ali, "Morphological, structural, and electrical characterization of sol-gel-synthesized ZnO nanorods," Journal of Nanomaterials, vol. 2013, Article ID 478942, 7 pages, 2013.

[18] S. K. Panda and C. Jacob, "Preparation of transparent $\mathrm{ZnO}$ thin films and their application in UV sensor devices," Solid-State Electronics, vol. 73, pp. 44-50, 2012.

[19] Z. Xu, H. Deng, J. Xie et al., "Photoconductive UV detectors based on $\mathrm{ZnO}$ films prepared by sol-gel method," Journal of SolGel Science and Technology, vol. 36, no. 2, pp. 223-226, 2005.

[20] M. H. Mamat, Z. Khusaimi, M. M. Zahidi, and M. R. Mahmood, "Performance of an ultraviolet photoconductive sensor using well-aligned aluminium-doped zinc-oxide nanorod arrays annealed in an air and oxygen environment," Japanese Journal of Applied Physics, vol. 50, no. 6, Article ID 06GF05, 2011.

[21] J. Zhou, Y. Gu, Y. Hu et al., "Gigantic enhancement in response and reset time of $\mathrm{ZnO}$ UV nanosensor by utilizing Schottky contact and surface functionalization," Applied Physics Letters, vol. 94, no. 19, Article ID 191103, 2009.

[22] S. S. Hullavarad, N. V. Hullavarad, P. C. Karulkar, A. Luykx, and P. Valdivia, "Ultra violet sensors based on nanostructured $\mathrm{ZnO}$ spheres in network of nanowires: a novel approach," Nanoscale Research Letters, vol. 2, no. 3, pp. 161-167, 2007.

[23] S. J. Chang, T. K. Lin, Y. K. Su et al., "Homoepitaxial ZnSe MSM photodetectors with various transparent electrodes," Materials Science and Engineering B, vol. 127, no. 2-3, pp. 164-168, 2006.

[24] Y. Jin, J. Wang, B. Sun, J. C. Blakesley, and N. C. Greenham, "Solution-processed ultraviolet photodetectors based on colloidal ZnO nanoparticles," Nano Letters, vol. 8, no. 6, pp. 16491653,2008 . 

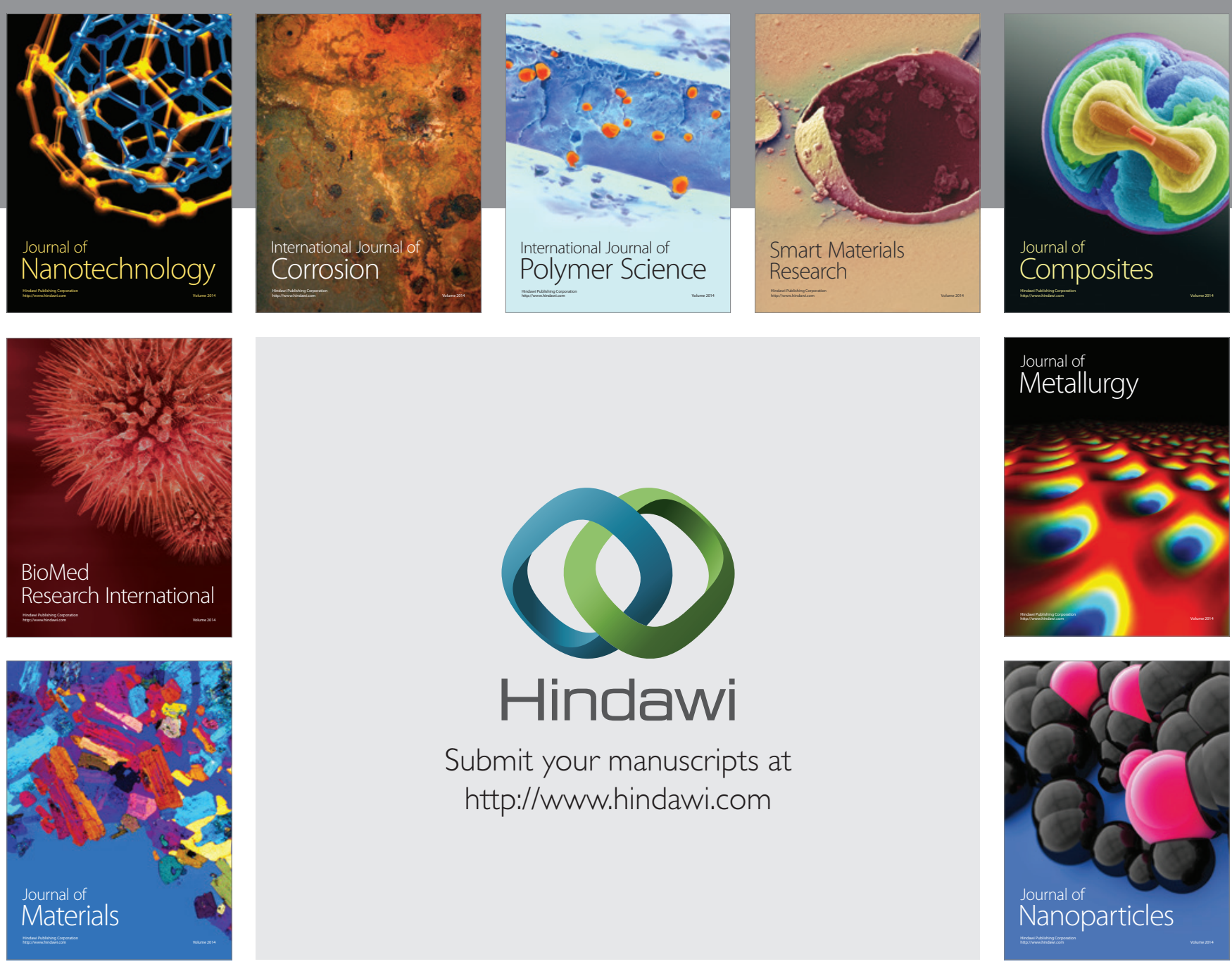

Submit your manuscripts at http://www.hindawi.com
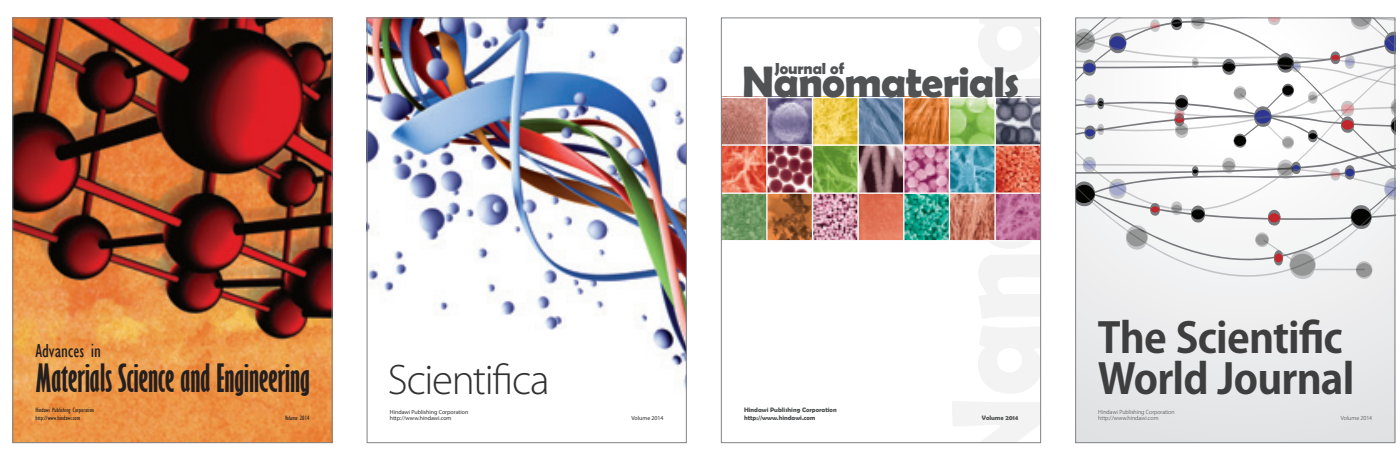

\section{The Scientific World Journal}
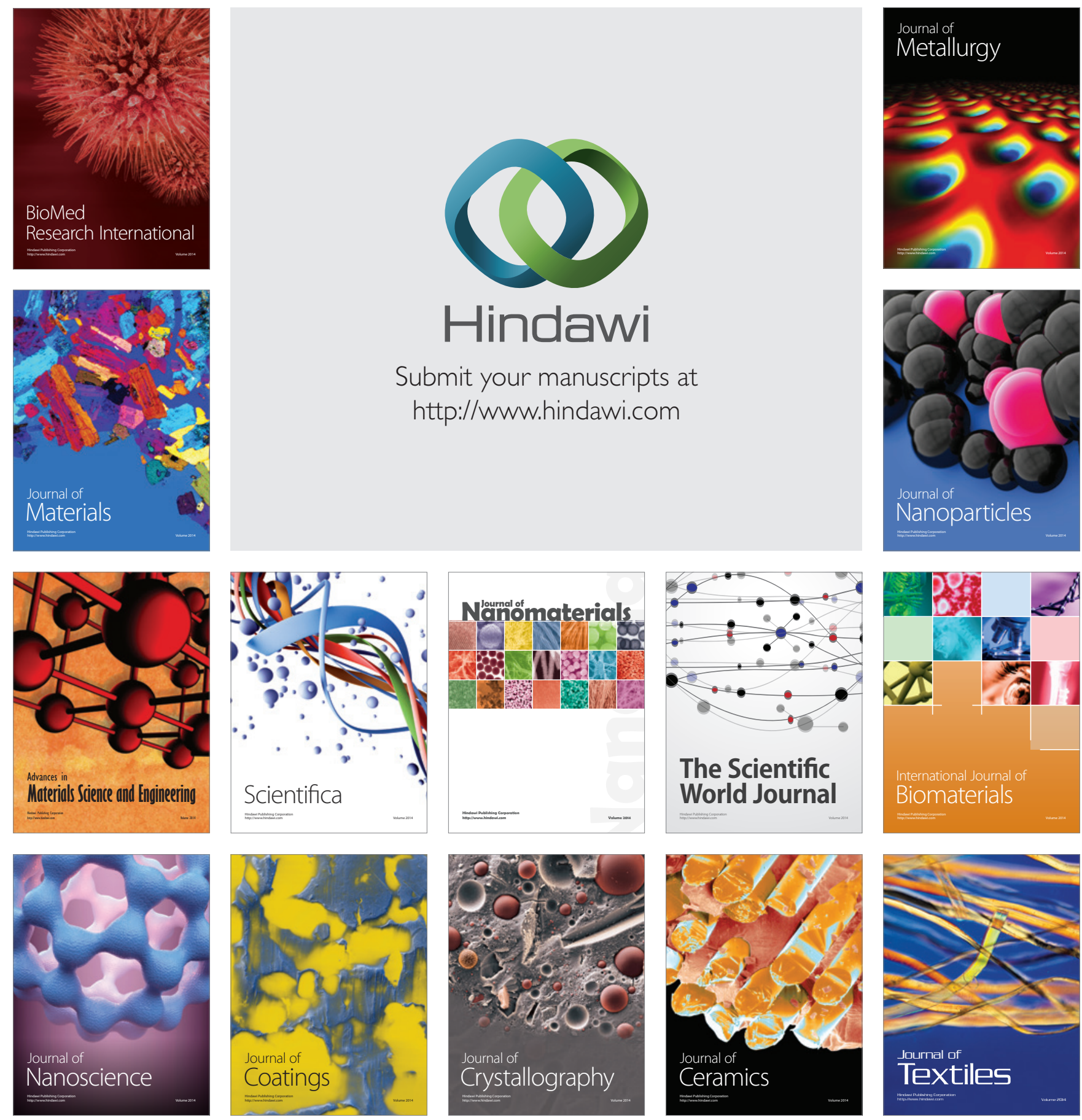